У ДК $536.46+534.222 .2+681.513+621.867 .81$

\title{
АЛГОРИТМЫ ОЩЕНКИ И СПОСОБЫ ОБЕСПЕЧЕНИЯ ВЗРЫВОБЕЗОПАСНОСТИ ЭЛЕВАТОРОВ
}

\author{
Понов А.С., аспирант \\ Одесская национальная академия пищевых технологий, Одесса
}

\begin{abstract}
Построены алгоритиы оиенки взрывоопасности элеватора на основе сочетания иатеиатических иоделей двух типов. ІІервый тип иодетеї базируется на теории нечетких иножеств и нечеткой тогике. Второй тии основан на классической теори горения и детонации. Указаны основные способы и средспва обеспечения взрывобезопас:ности э.теватиров

Algorithms for the grain elevator explosion-proof estimation are constructed on the base of two tupes of mathematical models The first type of models is based on the fuzzy-set theory and fuzzy logic. The second type is based on the probability theory and the classical theory of combustion and explosion. The main methods and means for the blast-proof guaranteeing are indicaled.
\end{abstract}

Ключевые слова: элеватор, пыль, взрыв, взрывобезопасность, пламя, горение, дефлаграция, детонация, алг оритм, нечеткая логика.

ІІроблема взрывобезопасности была и остается одной из важнейших и сложнейших проблем современного промышленного производства, в первую очередь - для химических, пицевых, зерновых и зерноперерабатывающих предприятий [1 -3], в том числе - элеваторов. ІІрактическое решение этой проблемы связано, в первую очередь, с соблюдением определенных правил техники безопасности при изготовлении, транспортировке, хранении и использовании пожаро- и взрывоопасных материалов. Эти правила изложены в многочисленных руководствах, стандартах и сиравочниках. Хотя упомянутые выше правила соблюдения пожаро- и взрывобезопасности охватывают почти все возможные на практике ситуации, тем не менее представляется целесообразным рассмотреть основные принципы обеспечения безопасности элеваторов. Это представляется чрезвычайно важным по следуюшим причинам

Во-первых, гравила техники безопасности, в том числе пожаро- и взрывобезопасности в производственных условиях далеко не всегда соблюдаются.

Во-вторых, никакие руководства, стандарты, предписания и справочники (некоторые из которых, кстати, в значительной степени устарели) не могут учесть все многообразие аварийных ситуаций, возникаюцих в условиях современного сложнейшего производства. Об этом свидетельствует и анализ статистических данных об аварийных и катастрофических ситуациях, связанных с возникновением взрывов на промышленных предприятиях [1-3].

В-третьих, весь смысл техники безопасности состоит в том, чтобы предотвратить возникновение аварийных ситуаций, однако необходимо решать еще по меньшей мере две проблемы: при возникновении аварийной (точнее, аварийноопасной) ситуации нужно предотвратить или, по меньшей мере замедлить, ее развитие, а в случае неизбежности аварии (в частности - взрыва) максимально ослабить ее разрушительный эффект, уменьшить ушерб и, по возможности, избежать человеческих жертв.

В четвертых, некоторые положения теории горения и взрыва, на базе которых созданы справочники и ГОСТы, периодически пересматриваются, что не всегда учитывается в производственных условиях достаточно оперативно.

На рис.І схематично указаны три параллельных комплекса мер для снижения степени риска взрыва при производстве, хранении и использовании материалов с “допустимой” степенью пожаро- и взрывобезопасности. Для обеспечения максимальной безопасности технологического процесса перечисленные комплексы мер должны использоваться совместно и в соответствующем сочетании .

Сначала рассмотрим пассивные методы обеспечения пожаро- и взрывобезопасности (см. левую часть Рис. 1), затем - активные методы, требующие вмешательства оператора или автоматических противопожарных и противовзрывных систем и, наконец, комплекс профилактических мероприятий (правая часть Рис. 1). 


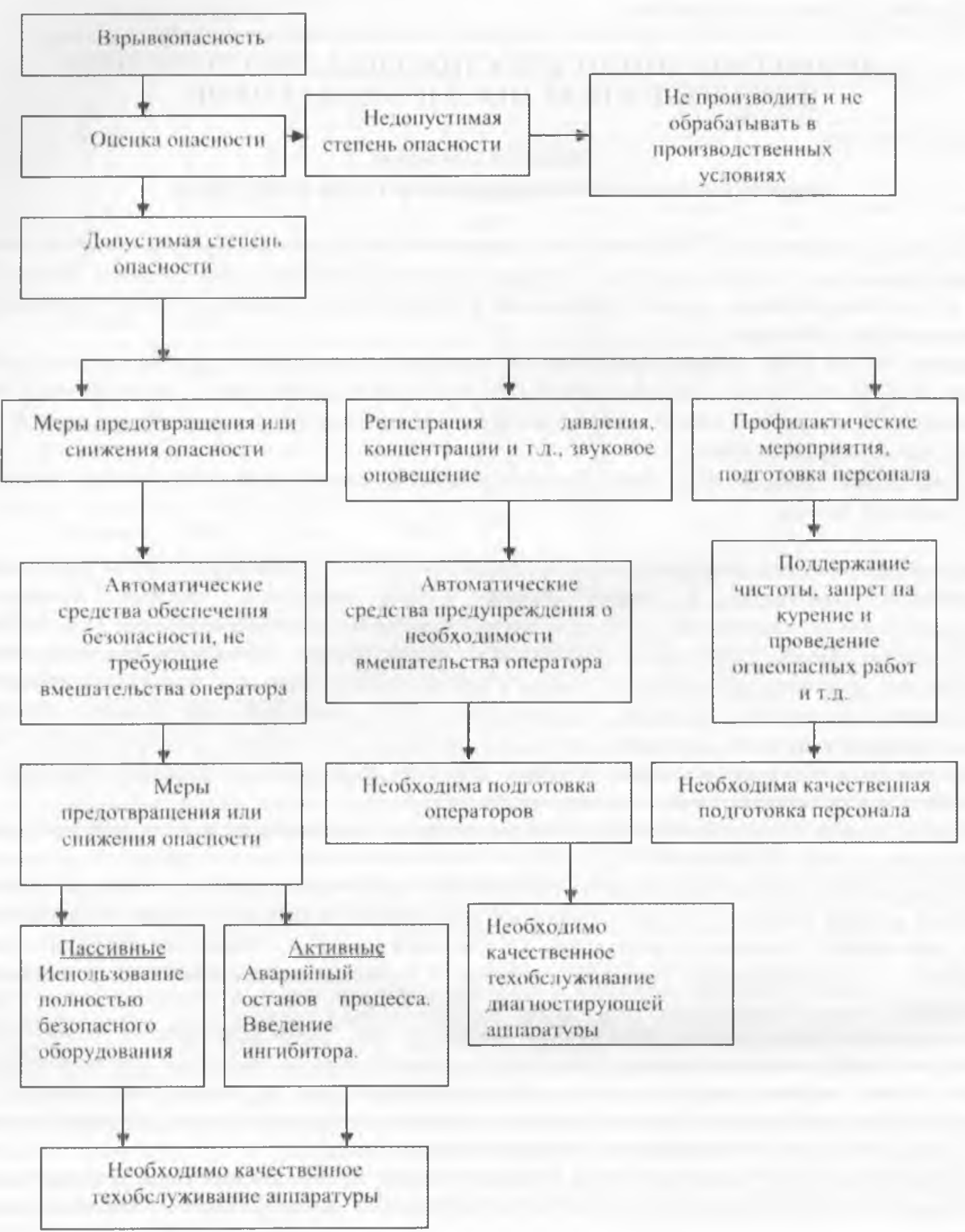

Рис. 1. - Комплексы мер для снижения степени риска взрыва

К пассивным методам можно отнести:

1) правильное (с точки зрения взрывобезопасности) проектирование предприятий, цехов и других объектов;

2) использование полностью безопасного и взрывозашищенного оборудования;

3) аварийный сброс давления;

4) ловушки пламени и детонации;

5) дожигание.

Примером крайне неудачного проектирования предприятия с точки зрения взрывобезопасности является конструкция элеватора «DE BRUCE» (Рис.2), взрыв которого имел место 8 июня 1998г. в городе Хайсвилл (Haysville), США [4] и был рассмотрен ранее $[5,6]$ с теоретических позиций. Чрезвычайно большая протяженность элеватора (по сравнению с шириной) сделала возможным переход горения в детонацию, в то время как прямое инициирование детонации естественным путем в производственных условиях невозможно Следует отметить, что длина преддетонационного участка для гомогенных газовых смесей ни при каких 
обстоятельствах не превынает 10 диаметров трубы $[2,7,8]$ (для широких труб, где силы вязкого сопротивления, препятствующих ускорению пламени не играют существенной роли), если детонация вообще возможна. В данном случае это соотношение превышено почти вдвое. Гаким образом, очевидна ошибка, допушенная при проектированип элеватора. Недопущение подобных ошнбок существенно препялствует переходу пожара в дефлаграционный взрыв, а развитой дефлаграции - в детонацию.

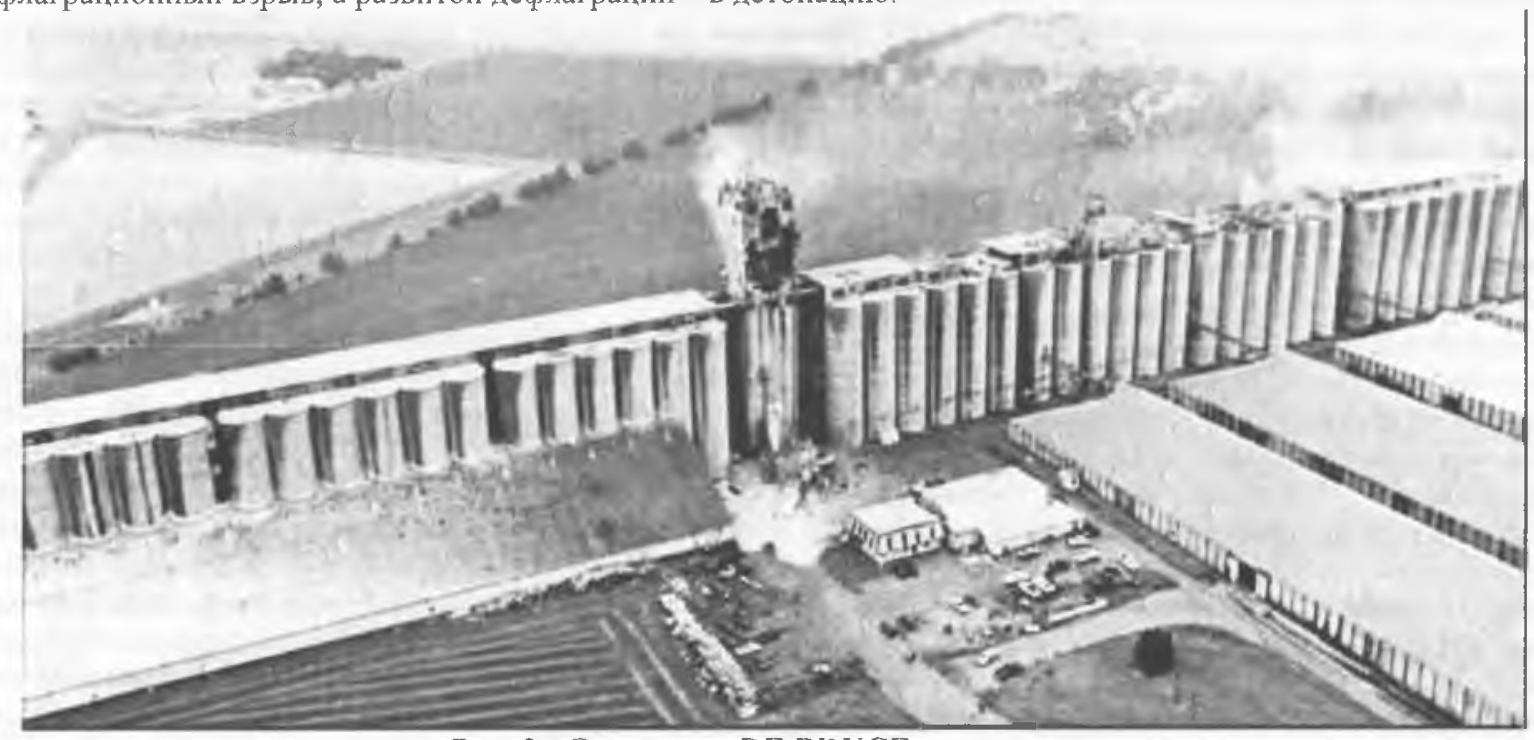

Рис. 2 - Элеватор «DE BRUCE» после взрыва.

Взрывозащищенное электрооборудование предназначено для использования в горкчих газовых, парогазовых и пылевых средах. При размещении оборудования в газовых и парогазовых системах считается, что горючая смесь может затечь внутрь защитного кожуха электрооборудования и воспламени'ься за счет электрической искры. Следовательно, электрооборудование, создаваемое для использования в гаких средах:

- не должно разрушаться в результате локального взрыва;

- должно иметь гредохранительные зазоры для истечения продуктов сгорания из кожуха, причем размер этих зазоров должен быть достаточно малым (меньше максимальног безопасног размера предохранительной шели), чтобы не произошло инициирования горючей смеси вне кожуха с оборудованием [2].

В случае пылегазовых сред считается, что пыль не может попасть внутрь зашитного кожуха, который при этом должен проектироваться с таким расчетом, чтобы температура его поверхности не превысила температуру воспламенения слоя пыли.

В некоторых случаях единственно возможным способом обеспечения безопасности функционирования электрооборудования во взрыво-и пожароопасных средах является надлув в запитные кожухи воздуха или инертного газа (например, азота). Этот способ существенно дороже непосредственного использования взрывозашищенного электрооборудования. Однако, если оборудование, размепцаемое во взрывоопасных средах, является очень чувствительным (как, например, датчики для измерения концентрации или расхода газа в трубопроводах), то оно не сможет выдержать нагрузок, возникаюшцх в результате "допустимого" взрыва внутрь зацитного кожуха. В этом случае во внутренний объем зацитного кожуха необхолимо постоянно полкачивать инертный газ или воздух, причем давление в этом внутреннем объеме, все время должно подлерживаться на повышенном уровне, чтобы исключить затекание газа внутрь зацитного кожуха.

Аварийный сброс давления возможен за счет разгерметизации реакторов и грубогроводов, использования мембран и легкосбрасываемых конструкций и т.п. [1,2,7]. Такое решение требует, как иравило, меньше затрат, чем меры, направленные на подавление пламени [7].

Еще один способ борьбы с распространением пламени по трубопроводам и друтим магистралям, а также в реакторах и зданиях, заключается в использовании огнецреградителей, или ловушек пламени. Конструкции таких огнепреградителей хорошо известны и обсуждаются в работах $[9,10]$. Гораздо труднее сконструировать ловушки детонации, поскольку такие ловушки должны обеспечивать гораздо большее снижение давления в системе, чем ловушки пламени. Пример успешного использования ловушки детонации приведен в работе [11], где описан случай искусственного срыва распространения детонации в ацетилене по трубопроводу длиной 11 км за счет использования пузырькового экрана непосредственно перед секцией с оборудованием.

Иногда при возникновении аварийной ситуации в технологическом процессе появляется необходимость выброса из реактора значительного количества горючей смеси, при этом эта смесь дожигается по мере ее истечения (дожигание).

К активным методам обеспечении пожаро- и взрывобезопасности относятся также методы, в которых при аномальном увеличении давления и температуры в реакторе, регистрируемых автоматическими датчиками, соответствуюшие противоаварийное устройство, например, вводит в реактор ингибирующие агенты для предотвращения взрыва или автоматически прекращает процесс. При использовании автоматических 
противоаварийных устройств особое внимание следует уделять их надежности во избежание возникновения ложных аварийных ситуаций. Для предотврашения подобных случаев представляется уместным применение систем гарантирующего управления, т.е. систем автоматического управления, реализующих функцию гарантирования: иаучные основы таких систем, включая применение их на практике (на иредприятиях шипевой промышленности в первую очередь), разработаны В.А.Хобиным [12].

Средства автоматического контроля. также реагируют на аномальное поведение параметров рабочего процесса, но соответствующие решения принимаются подготовленным для этой цели оператором. Для достижения желаемого успеха в этом случае важны не только высокая надежность диагностирующего оборудования, но и высокая квалификация обслуживающего персонала.

Комилекс профилактических мероприятий может быть весьма обширным и разнообразным, но обязательно должен включать в себя соответствующее обучение персонала. Наилучший способ обучения персонала правилам техники безопасности (ТБ), в т.ч. и пожаро- и взрывобезопасности, - это проведение регулярных занятий по шиирокой грограмме.

Правила пожарной безопасности ири проведении сварочных и других огневых работ, а также инструкции по организации безопасного проведения огневых работ на взрывоопасных и взрывопожароопасных объектах формулируют конкретные требования, направленные на исключение возможности возникновения взрыва. Например, ири организации подготовительных работ на предшриятиях ио хранению и переработке зерна все оборудование, - аппараты, машины, бункера, силосы, трубопроводы и т.П., - на котором предполагается проведение огневых работ, должно быть остановлено и очищено от пылевидных продуктов, представляющих пожаровзывоопасность. Кроме того, нужно оградить оборудование, на котором будут проводиться огневые работы, от действуюшего оборудования и эксплуатируемых коммуникаций ( для чего используются соответствуюшие заглушки и т.п. ) [1]. ЦІри этом строительные конструкции и металлоконструкции, находящиеся в зоне проведения огневых работ, тоже должны быть предварительно очищены от отложений пожаровзрывоопасных мелкодисперсных материалов. Регулярная уборка помещений и оборудования с целью недопушения образования взрывоопасной пылевоздушной смеси предусмотрена на всех мукомольных заводах и элеваторах, и вообше на всех производствах, где существует опасность возникновения пылевых взрывов. ІІри этом следует обратить внимание на тот факт, что часто запыление отдельных помещений часто наблюдается даже при формально хороших показателях работы аспирационной системы, когда пыль, взвешенная в воздухе, постепенно оседает на окружающей поверхности в виде достаточно тонкого и неплотного, а потому и легковзлетающего слоя - аэрогеля [1]. На предприятиях по хранению и переработке зерна допускается накопление слоя пыли не боле 0,5 мм $[1,2]$.

С нашей точки зрения для оценки взрывоопасности элеватора необходимо применение теории нечетких множеств и нечеткой логики [ll 13 16] в сочетании с классическими физико-математическими методами, базирующимися, главным образом, на теории неустойчивости и структуры волн горения и детонации [17-20]. Идея применения нечеткости и теории принятия решений в условиях неопределенности для ироблем, связанных со взрыво- и пожаробезопасностью, была впервые сформулирована в работе [21] и развита в серии следующих работ [22-25]. При этом вполне очевидно, что ограничиться только классическими моделями невозможно ввиду сложности проблемы, а применение методов теории вероятности и математической статистики представляется нецелесообразным по причинам, изложенным в [26]. Применение теории гидродинамической устойчивости дает возможность получения необходимых теоретических оценок без сложных численных расчетов на ЭВМ.

Алгоритма оценки взрывоопасности элеватора на основе вышеизложенных принципов предполагает следующие шаги:

1. Выделение потенциально взрывоопасных элементов элеватора. К ним можно отнести [I]

а) силосы и бункера;

б) нории;

в) аспирацпонные системы;

г) зерносушилки.

В особых случаях возможно выделение иных потенциально взрывоопасных элементов и объектов. Далее производится оценка взрывоопасности каждого из этих элементов.

2. Оценка взрывоопасности каждого отдельного элемента, указанного в шаге 1. Включает в себя следующие пункты.

2.1. Геометрическая характеристика объекта. Объект моделируется плоским каналом или круглой цилиндрической трубой (канал и груба могут быть открытыми, полуоткрытыми и замкнутыми). Если такое моделирование невозможно, данный объект разбивается на несколько элементов, каждый из которых рассматривается как отдельный элемент.

2.2. Характеристика стенок объекта. В первую очередь учитываются шероховатость и жесткость стенок

2.3. Характеристика физико-химического состояния среды, заключенной внутри потенциально взрывоопасного объекта. Такой средой на элеваторах является ПВС (пылевоздушная смесь). Включает в себя следующие подпункты.

2.3.а. Указание химического состава и химических свойств пыли. 


\section{3.б. Указание дисперсного состава пыли.}

2.3.в. Указание концентрации пыли в IIBC с точки зрения соблюдения или несоблюдения концентрационных пределов воспламенения - нижнего (НКІІВ) и верхнего (ВКІІВ).

2.3.г. Указание температуры IIBC и давления в IIBC.

2.4. Характеристика возможностей потенциального источника (источников) зажигания, сведенная к температуре и энергии зажигания.

2.5. Оценка пожароопасности объекта с точки зрения геории нечетких множеств на основе данных

2.3 и 2.4 Выражается нечеткой логической переменной $\Pi$, , представленной конъюнктивной формой

$$
\Pi_{i}=\bigwedge_{i=1}^{m} \Phi_{i}^{n},
$$

где

i - номер взрывоопасного элемента (объекта), $\mathrm{I} \leq \mathrm{i}<\mathrm{n}, \mathrm{n}-$ общее число взрывоопасных элементов (объектов);

$\Phi{ }_{1}^{l}$ - фактор, влияюций на пожароопасность, оцениваемый как $0 \leq \Phi_{i}^{I 7} \leq 1$ (нечеткая переменная в смысле Заде [13-16]);

j- номер фактора, влияющего на пожароопасность;

$\mathrm{m}$ - количество факторов, влияющих на пожароопасность.

При этом здесь и далее подразумевается минимаксная трактовка логических операций, введенная 3аде [13,14].

[Іримеры составления конъюнктивных форм вида (1) приведены в [24-26]. Если $I /$, $\approx 0$, то 1-ый объект не пожароопасен и, как следствие, не взрывоопасен.

2.6. Оценка взрывоопасности объекта с точки зрения теории нечетких множеств на основе данных 2.3

и 2.4, а также оценки 2.5. Выражается нечеткой логической переменной $B_{i}$, представленной конъюнктивной формой

$$
B_{i}=\bigwedge_{k=1}^{\prime} \Phi{ }^{B},
$$

где

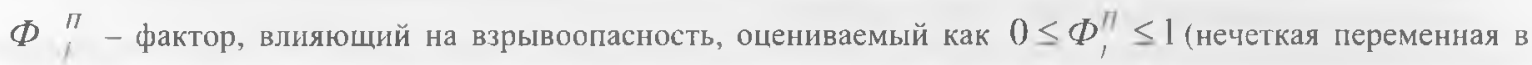
смысле Заде [7-10]);

k - номер фактора, влияющего на взрывоопасность;

1 - количество факторов, влияющих на взрывоопасность.

При этом $\exists 1 \leq j \leq l \Phi{ }_{i}^{n}=\Pi_{i}$

Для получения значений $\Phi, "$ можно использовать:

а) данные экспериментов (если они проводились);

6) информацию об аналогичных взрывах (если имели место);

в) результаты аналитических исследований, которые следует провести в соответствии с [17-19] на базе теории неустойчивости волн горения и детонации;

г) результаты численных расчетов на базе теории точечного взрыва [2] (если они проводились);

д) экспертные оценки, полученные, впрочем, на основе а)-д).

ІІринимается во внимание возможность не только дефлаграционного, но и детонационного взрыва элеватора. формой

3. Оценка взрывоопасности элеватора в целом на основе результатов 2.6. Выражается дизъюнктивной

$$
\tilde{B}=\bigvee_{i=1}^{n} B i
$$

В случае $B \cong 0$, то взрывоопасность элеватора в целом низкая, если же $B \cong 1$, то элеватор чрезвычайно взрывоопасен.

Обращает на себя внимание следующцй парадокс. Может быть получена оценка пожароопасности элеватора в целом на основе результатов 2.5. Она выражается дизъюнктивной формой

$$
\bar{\Pi}=\bigvee_{i=1}^{n} \bar{\Pi},
$$


В случае $\Pi \cong 0$, то пожароопасность элеватора в целом низкая, если же $\Pi \cong 1$, то элеватор чрезвычайно пожароопасен ІІри этом несложно убедиться, что формально не исключена ситуация, когда при $\Pi \cong 0$ имеет

место $B \cong 1$, т.е. при невысокой пожароопасности элеватора он может быть весьма взрывоппасным. Этот парадокс, однако, легко разрешим. В самом деле, низкая пожароопасность элеватора означает, чго вероятность возникновения очагов возгорания на элеваторе мала. Однако вероягность взрыва ири возникшем все же возгорании велика. В этом случае взрывоопасность элеватора в целом остается высокой. Взрыв элеватора «DE BRUCE» как раз является иримером подобной ситуации: источником зажигания, породившего пожар, а затем н взрыв, послужила оборвавшаяся лента транспортера, причем ввиду весьма неудачной конструкции элевалора, вытянутого в одном направлении более чем на $800 \mathrm{M}$, дефлаграция перешла в детонацию с крайне разрушительными последствиями [4-6]. ІІри сложившейся ситуации переход пожара на элеваторе во взрыв произошел почти мгновенно и был практически неизбежен.

Таким образом, построен алгоритм оценки как взрывоопасности элеватора в целом, так и взрывоопасности отдельных его элементов (объектов). Данный алгоритм реализован программно (в среде программирования Visual Basic) и составляет основу ситуационной советующей системы с нечеткой логикой (ССНJ) [16]. Эта ССНЛ, в свою очередь, является составной частью интеллектуальной системы подлержки принятия решений (CIIIP) по вопросам взрывобезопасности и взрывозащиты элеватора. Данная СIIIP позволяет управлять взрывобезопасностью элеватора как при его проектировании или реконструкции, так и при его эксплуатации.

\section{Литература}

I Васильев Я.Я., Семенов Л.И. Взрывобезопасность на предприятиях по хранению и переработке зерна. М.: Колос. $-1983 .-224 \mathrm{c}$.

2. Взрывные явления. Оценка и последствия: В 2-х кн. Кн.l / Бейкер У., Кокс II., Уэстайн II. и др. - М: Мир, 1986. $-319 \mathrm{c}$.

3. Бесчастнов М.В. ПІромышленные взрывы. Оценка и предупреждение- М.: Химия, 1991 - 432 с.

4. Kauffman C.W. The DeBruce Grain Elevator Explosion //Seventh International Symposium on Hazards, Prevention and Mitigation of Industrial Explosions: Thirteenth International Colloquim on Dust Explosions \& Eigth Colloquim on Gas, Vapor, Liquid, and Ilybrid Explosions. St. Petersburg, Russia. July 7-11, 2008. Si. Petersburg, 2008. - Vol.3. - P.3-26.

Волков В.Э., Понов А.С., Тришин Ф.А. Анализ причин взрыва элеватора «DE BRUCE» // Зерновые гродукты и комбикорма. - 2008. - №3 - С $40-44$

6. Волков В.Э., Макоед Н.А., Тришин Ф.А. Вопросы взрывобезопасности зерновых и пищевых производств //Іищевая наука и технология, 2008.№3, сентябрь 2008. С. 49-53.

7. Нетлетон М. Детонация в газах. - М.: Мир.- 1989. - 280с.

8. Щелкин К.И., Трошин Я.К. Газодинамика горения. - М.: Изд-во АН СССР.- 1963.-256c.

9. Стрижевский ІІ.И., Заказнов В.Ф. Промышленные огнепреградители. - М.: Химия, 1966. - 151с.

10. Howard W.B., Russell W.W. A Procedure for Designing Gas Combustion Venting Systems //Loss Prevention, 1972, 6 .

11. Sutherland M.E., Wegert H.W. An Acetylene Decomposition Incident //Loss Prevention, 1973. - Vol. 7. - P. 99103.

12. Хобин В.А. Системы гарантирующего управления: основы теории, практика применения: Автореф. дис докт. техн. наук. - Одесса, 2003. - 40 c.

13. Zadeh L.A. Fuzzy Sets. //Information and Control, 1965. - Vol. 8. - P. 338-353.

14. Заде JI. ГІонятие лингвистической переменной и его применение к принятию приближенных решений. - М: Мир, 1976. - $165 \mathrm{c}$.

15. Кофман А. Введение в теорию нечетких множеств. - М: Радио и связь, 1982. - 432 с.

16. Мелихов А.Н., Бернштейн Л.С., Коровин С.Я. Ситуационные советующие системы с нечеткой логикой. М.: Наука. Гл. ред. физ.-мат. лит., 1990. - 272 с.

17. Асланов С.К., Волков В.Э. Интегральный метод анализа устойчивости ламинарного пламени. - Физика горения и взрыва, 1991, №5. - C. 160-166.

18. Aslanov S., Volkov V. On the Instability and Cell Structure of Flames. - Archivum combustionis, 1992, Vol.12, Nr. 1-4. - P.81-90.

19. Асланов С.К., Волков В.Э., ІІаренко А.ІІ. Математический анализ структуры детонационных волн в различных средах. // Вестник ОГУ, -1999.-Т.4.Вып.4. Физ.-мат.науки-С. 134.

20. Волков В.Э. ІІределы детонации и проблемы взрывобезопасности. - Наукові праці Одеської національної академії харчових технологій. - Одеса, 2006. - Вип. 28 - С. 194-199.

21. Волков В.Э. Теоретические основы построения систем интеллектуальной поддержки принятия решений по вопросам взрывобезопасности //Информационные системы и технологин: Тез. докл. II-го семинара. Одесса. - 2004. - С. 6-7. 
22. Волков В.Э., Макоед Н.А. Теория нечетких множеств в экспертных системах по вопросам взрывобезопасности //Тез. докл. межлунаролной научно-практической конференции «Іищевые технологии-2006». - Одесса. - 2006. - С. 157

23. Волков В.Э. Интеллектуальные системы подлержки иринятия решений по вопросам взрывобезопасности //Зернові пролукти і комбикорми, 2007. - №2, червень 2007. - С. 44-47.

24 Волков В.Э., Жуковский Э.И. ІІринятие решений по вопросам взрывобезопасности в условиях неонределенности //Материалы международной научной конференция «Интеллектуальные системы принятия решений и проблемы вычислительного интеллекта (ISDMCI-2008)», 19-23 мая 2008 г., Евпатория, Укранна. Матерналы в 3-х гомах. Т.1, Ч.І. Херсон: ХІІТУ, 2008 C 37-40.

25 Волков В.Э., Жуковский Э.И. Проблемы уцравления взрывобезопасностью промышленных и трансіортных объектов //Доклады XV-ой международной научной конференции по автоматическому управлению «Автоматика-2008», 23-26 сентября 2008 г., Одесса, Украина В 3-х томах Т.1 Одесса: ОНМА, 2008. - С 9699 .

26 Волков В.э Теоретические основы принятия решений по вопросам взрывобезопасности //7ищевая наука и технология, 2008. - №2, июнь 2008. - С. 48-53.

\title{
ОСОБЕННОСТИ УІРАВЛЕНИЯ СУШИЛЬНЫМИ УСТАНОВКАМИ, ОТАПЛИВАЕМЫМИ ТВЕРДЫМ ТОПЛИВОМ, В ПИЩЕВОЙ ПРОМЫШЛЕННОСТИ
}

\author{
Воинова С. А., канд. техн. наук, доцент \\ Одесская национальная академия пищевых технологий \\ Вокнов А.П., доктор техн. наук, профессор \\ Одесский национальный политехнический университет
}

\begin{abstract}
Изложены особенности управления суиитьными установками пицевой проиыиленности при коиплекснои прииенении технологии кипяиего слоя на твердои топливе.

The features of control by drying units of a food industry at all-up applying of technology of fluid bed on solid fuel are enunciated. Voinova S. O. Features of control by drying units, heated by solid fuel, in food industry

Ключевые слова: управление, сушильная установка, твердое топливо, технология кипяцего слоя.
\end{abstract}

В пишевой промышленности, в сушильных установках, для подготовки сушильного агента (подогретого воздуха) применяют теплообменники газовоздушные (воздухоподогреватели), или паровоздушные (калориферы), использующие теплоту сжигаемого газообразного топлива (природного газа).

ІІредстоящий в Украине перевод значительной части огнетехнических установок с газообразного на твердое топливо выдвинул сложную научно-техническую задачу изыскания целесообразных методов, путей и средств его осуществления в каждом конкретном случае [1, 2]. Эта общая задача касается, в частности, используемых и создаваемых сушильных установок.

ІІри сжиганин газообразного топлива процесс горения и система автоматического управления (САУ) топочным устройством относительно просты. Однако они усложняются при сжигании твердого топлива.

Среди известных в промышленной энергетике технологий сжигания твердого топлива приоритетное положение по уровню эффективности занимает технология низкотемпературного пузырькового кипящего слоя [3 4]. Это обстоятельство обусловлено высокой экологической эффективностью топок этого типа и возможностью сжигать в них топливо любого вида и сорта, в том числе низкокачественное гвердое топливо При этом, следует указать на необходимость жесткого обеспечения технических требований к физикомеханическим свойствам твердого топлива, подаваемого в топку кипящего слоя, а именно, поддержания гранулометрического состава и содержания внешней влаги на уровне проектных значений. Если на предприятие поступает топливо иного качества, оно подлежит кондиционированию (дроблению) на угольном складе предприятия.

Система уюравления сушильной установкой содержит цве части:

- первая часть - САУ основным оборудованием - собственно сушилкой

- вторая часть - САУ вспомогательным оборудованием - источником сушильного агента (топкой или паровым котлом и подогревателем воздуха) 